Post-print of: Irrigation Science, Volume 33, Issue 5, September 2015, Pages 357-366

\title{
Using sap flow measurements to estimate net assimilation in olive trees under different irrigation regimes
}

Álvaro López-Bernal ${ }^{1 *}$ Omar García-Tejera ${ }^{1}$, Victorino A. Vega ${ }^{2}$, Juan C. Hidalgo ${ }^{2}$, Luca Testi ${ }^{1}$, Francisco Orgaz $^{1}$ and Francisco J. Villalobos ${ }^{1,3}$

${ }^{1}$ Instituto de Agricultura Sostenible (IAS), Consejo Superior de Investigaciones Científicas (CSIC), Av. Menéndez Pidal s/n, 14080, Córdoba (Spain)

${ }^{2}$ Instituto de Investigación y Formación Agraria y Pesquera (IFAPA-Alameda del Obispo), Av. Menéndez Pidal s/n, 14080, Córdoba (Spain)

${ }^{3}$ Dep. Agronomia, Universidad de Córdoba, Campus de Rabanales, Edificio C4, 14071, Córdoba (Spain)

*To whom correspondence should be addressed E-mail: g42lobea@uco.es Fax: +34 957499252 Tfn: $+34957499296$ 


\section{Abstract}

The measurement of bulk net assimilation $(A)$ in fruit tree species is hindered by the need for sophisticated and complex instrumentation. The aim of this study is to present a simple alternative for estimating $A$ from sap flow measurements and meteorological records. The proposed method was tested in a mature hedgerow olive orchard of 22.2 ha. Within the orchard, an irrigation experiment was established in a small plot including three treatments: a full irrigated control (CI), regulated deficit irrigation (DI) and a treatment mimicking customary orchard irrigation management (FI). Determinations of sap flow, water potential ( $\Psi)$ and trunk diameter variations (TDV) were conducted in the three treatments for three years. Also, measurements of net ecosystem exchange (NEE) were performed with an eddy covariance system in the centre of the orchard for the first season. The validity of the method was supported by the fact that estimates of $A$ were consistent with both the measured values of NEE and published data regarding the same species under similar environmental and management conditions. Also, differences in $A$ between irrigation treatments were generally in agreement with irrigation applied, transpiration $\left(E_{p}\right), \Psi$ and TDV. It is concluded that the proposed sap flow-based method represents a user-friendly approach to estimate $A$ at the canopy-level with potential to study the effects of deficit irrigation on biomass accumulation.

\section{Introduction}

Irrigated fruit tree culture in arid and semi-arid areas commonly takes place under conditions of water scarcity. This context has driven the development of deficit irrigation strategies (DIS) with successful results for increasing efficiency of applied water for a wide number of fruit tree species (Mitchell and Chalmers 1982; Goldhamer and Viveros 2000; Moriana et al. 2003; Fereres and Soriano 2007). The correct application of DIS requires accurate knowledge of the effects of water shortage on tree physiology, which has led to the search for robust and sensitive water stress indicators derived from plant-based measurements. Water potential ( $\Psi$, Jones 2004), canopy temperature (Jones 2004; Testi et al. 2008a), sap flow (Conejero et al. 2007; Fernández et al. 2008) and trunk diameter variations (Conejero et al. 2007; Fernández and Cuevas 2010) are among the water status indicators that have received more attention because of their potential for irrigation control. In an agronomical context, however, an indicator showing the effects of DIS on biomass 
production and, ultimately, yield is also desirable. In this regard, net assimilation rate $(A)$ should be a target indicator, but its determination remains challenging.

Leaf cuvette gas analyzers have been widely used to measure $A$ in mature trees (Moriana and Fereres 2002). These devices are reliable, but their operation is labour-intensive and non-automatable. In addition, scaling up measurements performed on a limited number of leaves to the whole canopy level might introduce errors. The use of large canopy chambers overcomes the latter issue, but their operation is unwieldy and requires sophisticated instrumentation (Perez-Priego et al. 2010). The eddy covariance technique can additionally yield useful information at the orchard scale, provided the measurements are performed within large uniform flat plots (Baldocchi et al. 2001). Unlike the former methods, this approach is suitable for automation, obtaining continuous estimates of the net ecosystem exchange (NEE). However, NEE is not only dependent on $A$ but also on the soil respiration of the plot, which in turn is affected by soil moisture and temperature (Law et al. 2002; Testi et al. 2008b).

Tree transpiration $\left(E_{\mathrm{p}}\right)$ can be determined by sap flow methods, which are based on the use of heat as a tracer of sap velocity (Swanson 1994). Such techniques have drawn increasing attention over the last decades because they are reliable, provide high frequency estimates of $E_{\mathrm{p}}$ and are well suited for automatic data collection (Green et al. 2003). Because the outward flow of water via stomatal openings is tightly coupled with the inward flow of $\mathrm{CO}_{2}$, we hypothesise that sap flow methods can provide an alternative approach to estimate $A$ at the canopy level. The objectives of this study were: 1) to present a simple automatable method for estimating $A$ from sap flow-based determinations of $E_{p}$ as well as 2) to validate the method and 3) to implement it in a mature olive orchard under different irrigation regimes.

\section{Materials and methods}

\section{Theoretical framework}

Net assimilation $\left(A, \mu \mathrm{mol} \mathrm{m} \mathrm{m}^{-2} \mathrm{~s}^{-1}\right)$ can be expressed as a function of the stomatal conductance to $\mathrm{CO}_{2}\left(G_{c}\right.$, $\left.\mu \mathrm{mol} \mathrm{m}^{-2} \mathrm{~s}^{-1}\right)$ as: 
$A=G_{c}\left(C_{a}-C_{i}\right)$

where $C_{a}$ is the $\mathrm{CO}_{2}$ concentration in the leaf boundary layer (set to $380 \mu \mathrm{mol} \mathrm{mol}{ }^{-1}$ ) and $C_{i}$ is the $\mathrm{CO}_{2}$ concentration in the substomatal cavity. In the case of ventilated canopies, such as fruit orchards, the magnitude of bulk aerodynamic conductance is very low in relation to $G_{c}$, which results in a tight coupling of canopies to the atmosphere. Under these circumstances, $G_{c}$ can be expressed as a function of transpiration $\left(E_{p}\right)$ by inverting the imposed evaporation equation:

$G_{C}=\frac{E_{p} P}{1.6 D}$

Where $D$ is vapour pressure deficit $(\mathrm{kPa}), P$ is atmospheric pressure $(\mathrm{kPa})$ and 1.6 is the ratio between the diffusion coefficients of $\mathrm{CO}_{2}$ and $\mathrm{H}_{2} \mathrm{O}$ in air.

In this study, $C_{i}$ was calculated as a constant fraction of $C_{a}$ (termed $\beta$ ), so the working equation to deduce an equivalent of $A$ from $E_{p}$ can be written as:

$A=\frac{E_{p} P}{1.6 D} C_{a}(1-\beta)$

In the case of olive (Olea europaea L.) trees, many studies show that $\beta$ values typically range between 0.5 and 0.6 (Centritto et al. 2005; Díaz-Espejo et al. 2006; Bacelar et al. 2007). We adopted the averaged value $(\beta=0.58)$ reported by Díaz-Espejo et al. (2006) for mature olive trees growing under similar environmental conditions to those in our experiments. By assuming constant values for both $C_{a}$ and $\beta$, the method requires only meteorological and sap flow records as inputs. Although the adoption of a constant $C_{a}$ should not lead to high errors (see Appendix S1 in the Electronic Supplementary Material with online version of this article), the accuracy of the method might be compromised by the fact that the coefficient $\beta$ could vary under conditions of changing water status (Brodribb 1996). The impact of this issue on the reliability of the proposed method is discussed below.

\section{$\underline{\text { Site description }}$}

The method was tested for three years $(2011,2012,2013)$ in a 22.2 ha hedgerow olive (cv. 'Arbequina') orchard located in 'La Harina' farm (Córdoba, Spain, $37.8^{\circ}, 4.8^{\circ} \mathrm{W}, 170 \mathrm{~m}$ altitude). The orchard was planted 
in 2005 with $4 \times 1.5 \mathrm{~m}$ spacing. During the course of the experiments, the height of the canopy was $\approx 3.2 \mathrm{~m}$ and had an average leaf area index of $1.5 \mathrm{~m}^{2} \mathrm{~m}^{-2}$. The soil was classified as a Vertisol (FAO classification) and the climate was Mediterranean. An automated weather station located at one of the orchard borders recorded the course of meteorological variables throughout the experiment. The station was composed of the following sensors: a sheltered air temperature and humidity probe (model HMP35, Vaisala, Helsinki, Finland), placed at $1.7 \mathrm{~m}$ height; a propeller wind monitor (mod 05103, RM Young, Traverse City, MI-USA), at 2 m height; a silicon cell pyranometer (model SKS 1110, Skye Instruments Ltd, Llandrindod Wells, Powys, UK), at $1.7 \mathrm{~m}$ height; and a tipping bucket rain gauge (produced in the IAS-CSIC laboratories, Córdoba, Spain), placed at $0.4 \mathrm{~m}$ height. The seasonal evolution of reference evapotranspiration $\left(\mathrm{ET}_{0}\right)$ and rainfall over the experimental periods is shown in Figure 1A-C. In 2011 and 2013 the study site was characterized by moderate to high precipitation in the winter-spring period (367 mm in 2011 and $508 \mathrm{~mm}$ in 2012 from January to June), whereas rainfall was very scarce in 2012 (90 mm from January to June). In all cases the summer was dry and hot (almost null precipitation and mean $\mathrm{ET}_{0}$ of $6.2 \mathrm{~mm} \mathrm{~d}^{-1}$ in July-August; Fig. 1A-C).

The orchard was drip-irrigated with three $2.2 \mathrm{~L} / \mathrm{h}$ emitters per tree with a maximum frequency of three times a week. The amount and distribution of irrigation was decided by the orchard manager and varied between years. In particular, irrigation was applied from late spring to early autumn and the dose ranged between 35 and $70 \%$ of the maximum estimated evapotranspiration (Fig. 1D-F, grey line).

In order to test the proposed method under different watering regimes, three irrigation treatments were established on separate plots of 40 trees in 4 adjacent rows in one of the orchard corners. Treatments were:

1. Control irrigation (CI): aimed to supply sufficient water to maintain maximum evapotranspiration (ET) throughout the irrigation season. To this end, irrigation doses were estimated as the difference between ET and rainfall, computing ET from the product of $\mathrm{ET}_{0}$ and the crop coefficient. The later was set to 0.75 , a value that was considered high enough to avoid water stress as evidenced by measurements of shoot $\Psi$ (described below). Irrigation was applied three times a week.

2. Regulated deficit irrigation (DI): irrigation was exactly the same as for CI except for a midsummer period (typically July-August) when the dose was lower and applied once or twice a week. The 
irrigation supplied during the deficit period was 50,50 and $35 \%$ of the quantity applied to CI in 2011, 2012 and 2013, respectively.

3. Farm management (FI): irrigation amount and frequency was according to the habitual commercial orchard management. The accumulated amount of irrigation was 70, 65 and $35 \%$ of that of CI in 2011, 2012 and 2013, respectively.

Further details concerning the seasonal application of irrigation for each treatment and year are depicted in Figure 1D-F.

$\underline{\text { Sap flow measurements }}$

Measurements of sap flow based on the compensated heat pulse technique (Swanson and Whitfield 1981) were performed in the plots with different irrigation treatments for the three irrigation seasons. Two of the central trees of each irrigation treatment were instrumented with sap flow sensors (one per tree, always in the trunk at a height of $30 \mathrm{~cm}$ from the soil and below main branches). The probes were designed and produced in the IAS-CSIC laboratory in Córdoba, Spain and consist of a $4.8 \mathrm{~W}$ stainless steel heater of $2 \mathrm{~mm}$ diameter and two temperature sensors of the same diameter located 10 and $5 \mathrm{~mm}$ down- and upstream of the heater, respectively (Testi and Villalobos 2009). Each temperature probe had four embedded Type E (chromelconstantan wire) thermocouple junctions, spaced $10 \mathrm{~mm}$ along the needle, that were sampled separately to obtain heat-pulse velocities at 5, 15, 25 and $35 \mathrm{~mm}$ below the cambium at 15-min intervals. Sensors were installed at $50 \mathrm{~cm}$ height from the soil and the system was controlled by a datalogger (CR1000, Campbell Scientific Inc., Logan, UT, USA). Heat-pulse velocities were corrected for wounding effects according to Green et al. (2003) and converted to sap flux densities from water fractions that were obtained from coresampling at the end of each measurement season. In addition, the 'calibrated average gradient' procedure (Testi and Villalobos 2009) was applied to calculate low sap velocities. Finally, sap flow values were deduced by integrating sap flux densities first across the trunk radius (using the radial velocity profile curve given by the probe) and then around the azimuth angle (Green et al. 2003).

To avoid errors associated to the natural azimuthal variability in sap flow rates (López-Bernal et al. 2010), the sap flow records were calibrated using the model of Villalobos et al. (2013), which allows the estimation of the daily transpiration $\left(E_{p, e s t}, \mathrm{~mm} \mathrm{~d}^{-1}\right)$ as a function of total daily solar radiation $\left(R_{s d}, \mathrm{MJ} \mathrm{m}^{-2} \mathrm{~d}^{-1}\right)$ : 
$E_{p, e s t}=37.0810^{-3} \frac{f R_{s d}}{a+b D_{m}} \frac{D_{m}}{P}$

where $f$ is the fraction of photosynthetically active radiation (PAR) intercepted by the canopy (dimensionless), $D_{m}$ is the averaged daytime vapour pressure deficit $(\mathrm{kPa})$ and the coefficient $37.08 \cdot 10^{-3}$ incorporates the conversion of units for Joules of solar radiation to $\mu \mathrm{mol}$ quanta and from mol to $\mathrm{kg}$ of $\mathrm{H}_{2} \mathrm{O}$. The parameters $a$ $\left(\mu \mathrm{E} \mathrm{mol}{ }^{-1}\right)$ and $b\left(\mu \mathrm{E} \mathrm{mol}{ }^{-1} \mathrm{KPa}^{-1}\right)$ were taken from Villalobos et al. (2013) and they are related to the radiation use efficiency and to the species-specific response to $D_{m}$. Radiation interception was computed using the model of Mariscal et al. (2000). This model calculates the PAR transmittance, at any given time, in the nodes of a three-dimensional grid inside a prism. The prism, of selectable height and grid density, is delimited by four adjacent trees. By spatial and time integration, the PAR intercepted during any given period can be calculated taking separately into account direct-beam radiation, diffuse radiation and scattering. Leaf area density, which is a required input for the model, was estimated from measurements of canopy transmittance conducted with a plant canopy analyzer (LAI-2000, Li-Cor, Lincoln, NE, USA). As the trees were regularly pruned each winter and the measurements of canopy transmittance were typically performed at the end of spring (before or soon after differences in irrigation between treatments were imposed), the estimated values of leaf area density were averaged and, hence, the same radiation interception was assumed for all the treatments.

As the model is only valid for unstressed canopies, Equation 4 was applied for one single sunny day per season in which measurements of $\Psi$ ensured no differences between treatments and good water status. Calibration coefficients for each tree were then computed as the ratio of measured sap flow values to $E_{p, \text { est }}$ and assumed to remain constant throughout each season. Finally, the calibrated sap flow values from sunrise to sunset were used as estimates of $E_{p}$ for the calculations of $A$ with Eq. 3.

\section{$\underline{\text { Eddy covariance measurements }}$}

The net ecosystem exchange (NEE, $\mu \mathrm{mol} \mathrm{CO} \mathrm{Cm}^{-2} \mathrm{~s}^{-1}$ ) of the orchard was measured with an eddy covariance system, installed at $6 \mathrm{~m}$ height atop a mast (EC tower). The mast was placed near the centre of the orchard, to ensure a minimum of $200 \mathrm{~m}$ and a maximum of $285 \mathrm{~m}$ of fetch in the direction of the more frequent winds and no interference from the sector where different irrigation treatments were applied. The system consisted 
of a three-dimensional sonic anemometer (model CSAT3, Campbell Scientific Inc., Logan, Utah, USA) and an open path $\mathrm{CO}_{2} / \mathrm{H}_{2} \mathrm{O}$ analyzer (model LI7500, LI-COR Biosciences, Lincoln, Nebraska, USA), and took continuous measurements from 24 June 2011 (DOY 175) to 27 September 2011 (DOY 270). Measurements of air temperature and relative humidity were acquired close to the anemometer with a combined probe (model HMP45C, Vaisala, Helsinki, Finland). All the sensors were connected to a data logger (model CR1000, Campbell Scientific Inc., Logan, Utah, USA) that recorded all the measurements with a sampling rate of $10 \mathrm{~Hz} . C_{a}$ concentration was measured at two heights $(0.3$ and $3.0 \mathrm{~m})$ with a closed-path $\mathrm{CO}_{2}$ analyzer (model LI-820, LI-COR Biosciences, Lincoln, Nebraska, USA) during the night to calculate $\mathrm{CO}_{2}$ storage.

The raw data were processed using Turbulent Knight 3 software (Mauder and Foken 2011) to calculate the NEE for 30-minute periods. All the relevant corrections were applied: coordinate rotation, spectral corrections, WPL corrections (Foken et al 2012). Finally, the NEE of daytime hours (filtered by net radiation $>50 \mathrm{~W} \mathrm{~m}^{-2}$ ) were integrated to obtain daily values in $\mathrm{g} \mathrm{CO}_{2} \mathrm{~m}^{-2} \mathrm{~d}^{-1}$ which were compared with the estimates of $A$ corresponding to FI trees in the separated experimental plot.

\section{$\underline{\text { Additional measurements in the irrigation treatment plots }}$}

Water potential $(\Psi)$ was determined using a pressure chamber (Soil Moisture Equipment Corp., Santa Barbara, CA, USA). Values of predawn and midday $\Psi$ were recorded twice a month from June to October for the three years. In each measurement, four sun-exposed shoots from the canopy top (with 1 to 3 leaf pairs attached) were sampled per treatment (shoots were always taken from one of the trees instrumented with sap flow probes).

Trunk diameter variations (TDV) were monitored with Linear Variable Differential Transducer dendrometers (LVDT; Model DF 2.5, Solartron Metrology, West Sussex, UK) mounted in a holder built of aluminium and 'INVAR'. One tree per irrigation treatment (one of the two instrumented with sap flow probes) was instrumented. In 2012 trunk diameter variations were only recorded in two trees (CI and DI). The sensors were attached in locations free of scars at about $0.4 \mathrm{~m}$ from the soil. The contact point of each dendrometer was glued to the surface of the living tissues of the bark with standard mastic for pruning wounds. Measurements were taken every $5 \mathrm{~min}$ and the system was controlled by a datalogger (CR1000, Campbell 
Scientific Inc., Logan, UT, USA). The daily values of maximum trunk diameter (MXTD) were used to give insight into the seasonal dynamics of trunk growth.

\section{Results}

Comparison with eddy covariance measurements

Figure 2 presents a time series of daily NEE deduced from eddy covariance, $A$ calculated from sap flow measurements and $D$ for the 2011 season. Both values of $A$ and NEE showed moderately fluctuating patterns, with the former being always slightly higher than those of NEE. In general, the highest values of both $A$ or NEE coincided with cloudy days with low $D$ whereas the minimum values occurred on sunny days of high $D$. Considering the whole period, average values of $A$ and NEE were 21.5 and $16.3 \mathrm{~g} \mathrm{CO}_{2} \mathrm{~m}^{-2} \mathrm{~d}^{-1}$, respectively. The differences in $A$ between the two instrumented trees was generally small (the average standard deviation for the period of comparison with measurements of NEE was $1.22 \mathrm{~g} \mathrm{CO}_{2} \mathrm{~m}^{-2} \mathrm{~d}^{-1}$ ) The averaged values of $A$ are plotted versus those of NEE in Figure 3, evidencing that both variables were tightly coupled. Linear regression analysis showed a good fit $\left(\mathrm{r}^{2}=0.819, \mathrm{P}<0.001\right)$ with a slope close to one and a positive intercept.

$\underline{\text { Responses of } A \text { and classical water status indicators to long-term deficit irrigation }}$

The CI treatment showed mean values of $\Psi$ around -0.5 and $-1.6 \mathrm{MPa}$ at predawn and midday, respectively, with little variation between years (Fig. 4A-C). By contrast, the patterns of $\Psi$ in both FI and DI varied with season, with 2011 being the year with the least differences between treatments. For DI, $\Psi$ generally decreased at midsummer, reaching midday values of $-2.1,-2.7$ and $-2.4 \mathrm{MPa}$ in 2011, 2012 and 2013, respectively. The $\Psi$ values of the FI treatment were similar to those of DI in 2011 and were intermediate (i.e. between those measured for DI and CI) in 2012 and 2013.

Figure 4D-F depicts the time course of MXTD for each treatment and year, relative to the values recorded at dawn of DOY 170, considering these as zero. After differential irrigation was applied, the MXTD patterns rapidly varied between treatments with CI exhibiting the highest values. Water deprivation resulted in lower trunk growth for DI and FI and even in moderate shrinkage during the summer of 2013. Both CI and DI had 
higher cumulative trunk growth in 2012 in relation to 2011 and 2013. For instance, CI grew 2.0, 4.0 and 1.7 $\mathrm{mm}$ in the period from DOY 170 to DOY 270 of 2011, 2012 and 2013, respectively.

The seasonal course of $E_{p}$ in CI trees (Fig. 4G-I) followed peaking patterns with the values reaching a maximum between mid-June and mid-July (DOY 165-200, $E_{p}$ around 3.5-4.0 $\mathrm{mm} \mathrm{d}^{-1}$ ) which was followed by a progressive decrease towards autumn. By contrast, behaviour of $A$ was more erratic (Fig. 4J-L), with the highest values (30-40 $\left.\mathrm{g} \mathrm{CO}_{2} \mathrm{~m}^{-2} \mathrm{~d}^{-1}\right)$ in spring and autumn, as well as on some summer days with low evaporative demand. Considering the period from 19 June (DOY 170) to 27 September (DOY 270), average $A$ values were $24.8,19.9$ and $23.3 \mathrm{~g} \mathrm{CO}_{2} \mathrm{~m}^{-2} \mathrm{~d}^{-1}$ in 2011,2012 and 2013 , respectively. The values of $E_{p}$ and $A$ in the other treatments were similar to those of CI early in the season and lower during the periods of water deprivation. It is noteworthy that Figure 4G-L shows the average $E_{p}$ and $A$ for each treatment. The variability between the two instrumented trees in each treatment was not presented both because it was generally small (standard deviations were, on average, around $0.21 \mathrm{~mm}$ and $2.0 \mathrm{~g} \mathrm{CO}_{2} \mathrm{~m}^{-2} \mathrm{~d}^{-1}$ for $E_{p}$ and $A$, respectively) and for the sake of clarity.

The effects of deficit irrigation on $A$ are further illustrated in Figure 5 by presenting the ratio of $A$ values for each treatment to those of CI. In the first season, similar patterns of $A$ were found both for FI and DI, with the values decreasing to $75-85 \%$ in relation to those of CI at midsummer. In 2012 , higher relative reductions were found, particularly in the case of DI, which reached values around 60-70\% of those of CI prior to the irrigation recovery phase in September. Finally, in 2013 DI showed decreasing $A$ trends during the summer, reaching minimum relative values in August (55-65\% of those of $\mathrm{CI}$ ). The highest relative reductions in $A$ for FI appeared in early summer and in September (around 60-65 \% of CI).

\section{Discussion}

Validity and strengths of the method

This study presents a new simple method for estimating $A$ in tree species. Its theoretical framework is based on the fact that both the outward loss of water vapour and the inward uptake of $\mathrm{CO}_{2}$ are driven each by diffusion through stomata. Thus, $A$ can be estimated from the value of $G_{c}$ (Eq. 1), which in turn can be 
approached in the case of fruit trees by the inversion of the imposed evaporation equation (Eq. 2) from $E_{p}$ and $D$ records (Orgaz et al. 2007; Villalobos et al. 2013). Using sap flow measurements to monitor $E_{p}$, the estimation of $A$ becomes particularly suitable and easy to implement: the proposed method is automatable, provides values which are representative of the whole canopy and uses inexpensive instrumentation. The advantages of employing sap flow measurements to assess gas exchange in trees have previously been acknowledged. In fact, they have been applied to estimate stomatal conductance to water vapour at the canopy level in several studies (e.g. Tognetti et al. 2009; Villalobos et al. 2013). Furthermore, Wieser et al. (2003; 2006) developed a similar sap flow-based method to the one described in this work to quantify the rate of ozone uptake in some forest tree species.

The close agreement between NEE and $A$ patterns shown in Figure 2 as well as the good fit $\left(r^{2}=0.82\right)$ and unit slope in Figure 3 are indicative of the reliability of the proposed method to monitor $A$ under field conditions. The higher values found for $A$ were expected, as NEE integrates the rates of $A$ as well as those of soil and woody-organ respiration. Our results suggest that such respiration rates, deduced as the difference between $A$ and $\mathrm{NEE}$, were on average $\approx 5 \mathrm{~g} \mathrm{CO}_{2} \mathrm{~m}^{-2} \mathrm{~d}^{-1}$, with slightly lower values appearing at midsummer (Fig. 2). In an irrigated olive (cv. 'Arbequina') orchard under similar environmental conditions, Testi et al. (2008b) measured soil respiration both in the alley and in the permanently wet zones near the drippers on a summer day. The average values were 1.1 and $5.7 \mu \mathrm{mol} \mathrm{CO} \mathrm{m}^{-2} \mathrm{~s}^{-1}$ in the alley and beneath the canopy, respectively, both remaining rather constant throughout the day. If these values are weighted considering the soil wetted fraction and integrated along the daytime, a rate of soil respiration of $2.9 \mathrm{~g} \mathrm{CO}_{2} \mathrm{~m}^{-2} \mathrm{~d}^{-1}$ can be calculated. This relatively low value can be attributed either to actual differences in respiration between both orchards (400

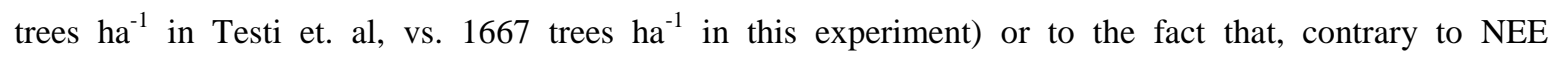
measurements, our $A$ estimates do not account for wood respiration. In any case, the proposed method yielded reasonable estimates of $A$.

The estimates of $A$ obtained under different irrigation regimes were also consistent with the findings of Villalobos et al. (2012), who used canopy chambers for measuring $A$ in well- and deficit-irrigated olive (cv. 'Arbequina') trees during a two-year experiment. In August, when their irrigation treatments were very similar to those applied in 2013 to our CI and DI treatments, the diurnal values of $A$ ranged between 11.1 and $21.3 \mathrm{~g}$ 
$\mathrm{CO}_{2} \mathrm{~m}^{-2} \mathrm{~d}^{-1}$ for well-irrigated trees and between 7.1 and $12.9 \mathrm{~g} \mathrm{CO}_{2} \mathrm{~m}^{-2} \mathrm{~d}^{-1}$ in the case of the deficit-irrigated ones. Compared to those, our daily estimates of $A$ in August 2013 were slightly higher, but the averaged values (20.5 $\mathrm{g} \mathrm{CO}_{2} \mathrm{~m}^{-2} \mathrm{~d}^{-1}$ for $\mathrm{CI}$ and $12.0 \mathrm{~g} \mathrm{CO}_{2} \mathrm{~m}^{-2} \mathrm{~d}^{-1}$ for DI, Fig. $4 \mathrm{~L}$ ) remained within the range reported (Villalobos et al. 2012).

\section{$\underline{\text { Potential methodological issues }}$}

In order to make the proposed method simple and easy to implement, its working equation (Eq. 3) assumes $C_{a}$ and $\beta$ as constants. While ignoring the natural variations is in $C_{a}$ is rather irrelevant (see Appendix $\mathrm{S} 1$ in Electronic Supplementary Material with online version of this article), adopting a fixed $\beta$ might compromise the accuracy of the method under certain conditions. Many reports claim that water stress results in reductions in $\beta$ because stomatal closure triggers a $\mathrm{CO}_{2}$ "supply" limitation of photosynthesis depleting $C_{i}$ (Kramer and Boyer 1995; Brodribb 1996). By contrast, others argue that plants have evolved feedback and feedforward mechanisms to keep the importation and depletion of $\mathrm{CO}_{2}$ in balance, so that both $C_{i}$ and $\beta$ are conservative provided that stress conditions develop gradually (Wong et al. 1979; Steduto et al. 2007). Although exceptions can be found (e.g. walnut, Rosati et al. 2006), most reports in fruit tree species show that $\beta$ tends to remain constant. Evidence of $\beta$ stability has been shown for almond (DeJong 1983; Marsal et al. 1997; Romero et al. 2004), hazelnut (Marsal et al. 1997) and orange trees (Pérez-Pérez et al. 2008). In the case of olive trees, the effect of water stress on $\beta$ seems also to be slight. For instance, Centritto et al. (2005) and Bacelar et al. (2007) worked in separate experiments with mature olive trees exposed to contrasting conditions of irrigation supply and both of them found no apparent relationship between the degree of water stress and the value of $\beta$, measured with leaf gas analyzers. In the same line, Villalobos et al. (2012) performed simultaneous measurements of gas exchange with large canopy chambers in well and deficit irrigated trees and found that the instantaneous transpiration efficiency (i.e. the ratio of $A$ to $E_{p}$ ) was always similar or only slightly higher for the later. As the differences in instantaneous transpiration efficiency should be proportional to the differences in $\beta$ (according to Eq. 3), the results of Villalobos et al. (2012) again suggest that, at most, water stress leads to very slight decline in $\beta$ in olive trees.

From a theoretical perspective, the method will tend to underestimate $A$ in the event of $\beta$ being significantly reduced by water stress, as $A$ is directly proportional to the term $1-\beta$ in Eq. 3. If this had been the case in our 
experiments, the estimates of $A$ for both DI and FI treatments would have been lower than the actual values at the periods with higher water restrictions (mostly concentrated in 2012 and 2013). Additionally, assuming a constant $\beta$ should tend to magnify the differences between well-watered and water-stressed conditions, which to some extent is useful for detecting the occurrence of reductions in $A$ in response to water deficits.

Finally, the method has practical limitations intrinsically related to the use of sap flow techniques to determine $E_{p}$. For example, obtaining proper estimates of $A$ requires either a large number of sensors per monitored tree or sap flow records to be calibrated (which require additional field measurements) because of the naturally-occurring heterogeneities in sapwood functioning (López-Bernal et al. 2010).

\section{$\underline{\text { Comparison with classical indicators of water status }}$}

The seasonal patterns of $\Psi$, MXTD, $E_{p}$ and $A$ showed marked differences between treatments (Fig. 4 \& 5) which were generally coherent with the amount and temporal distribution of irrigation water (Fig. 1D-F). The irrigation applied to DI during the summer period was much higher in 2011 than in 2012 and 2013, leading to higher $\Psi, E_{p}$ and $A$ in the first year. Moreover, 2013 was the year with the largest differences between treatments in the distribution and amount of irrigation, which also had a clear impact on the trends of $\Psi, E_{p}$ and $A$. For instance, the delayed start of irrigation in early summer 2013 and the water deprivation imposed in autumn for FI (Fig. 1F) resulted in low values of $\Psi, E_{p}$ and $A$ in relation to those of CI in these periods, while the greatest relative declines in DI were observed by midsummer, just prior to the recovery phase in September. The general agreement found between the course of $A$ and that of the other water stress indicators supports the feasibility of the proposed method to assess the effects of deficit irrigation on gas exchange and biomass accumulation. Furthermore, the seasonal dynamics of MXTD were also affected by the imposed irrigation treatments: as the summer progressed, values of MXTD in the deficit treatments diverged from those of CI indicating a reduction in trunk growth (Fig. 4D-F). These results seem to be in accordance with several studies indicating the possibility of using the difference in MXTD between full and DI trees as an early indicator of water stress (Fernández et al. 2011; Cuevas et al. 2013). Finally, the higher cumulative trunk growth found in 2012 in relation to that in 2011 and 2013 might be associated to the alternate bearing behaviour of olive trees. In this regard, fruit load was high in 2011, low in 2012 and high again in 2013 (yield 
in the CI plot was measured the three years, accounting 14.9, 7.1 and $11.4 \mathrm{t} \mathrm{ha}^{-1}$ in 2011,2012 and 2013 , respectively).

\section{Conclusions}

This study presents a simple approach for estimating $A$ in trees. Requiring only meteorological and sap flow records, the proposed method represents a user-friendly alternative to currently available measurement techniques. The method is automatable, works at the canopy-level and does not require special orchard or tree characteristics. Results of our experiments in a hedgerow olive orchard supported the validity of the method as the estimates of $A$ were consistent with both measurements of NEE performed using the eddy covariance technique and published data on the same species under similar conditions. Contrarily, the method is limited by the need of calibration of sap flow techniques and its accuracy remains unclear for those species or circumstances for which changes in water status lead to marked variations in $\beta$. Future research on these issues will help to improve the reliability of the method. Last but not least, it is worthy to stress that the method has potential to assess the effects of DIS on $A$, which might be useful to complement the information provided by other classical water stress indicators.

\section{Acknowledgements}

This work was funded by the Andalusian Regional Government (Junta de Andalucía, project P10-AGR-6456) and the Spanish Ministry of Economy and Competitiveness (MINECO, project AGL-2010-20766) and European Regional Development Fund (ERDF). In addition, we thank the Spanish Research Council (CSIC) predoctoral JAE program and again the aforementioned project AGL-2010-20766 for providing the Ph.D. scholarship granted to the first and second author, respectively. Besides that, the authors also acknowledge the excellent technical support provided by Mr Rafael del Río, Mr Ignacio Calatrava and Mr José Luis Vazquez.

\section{References}


Bacelar EA, Santos DL, Moutinho-Pereira JM, Lopes JI, Gonçalves BC, Ferreira TC, Correia CM (2007) Physiological behavior, oxidative damage and antioxidative protection of olive trees grown under different irrigation regimes. Plant Soil 292: 1-12.

Baldocchi DD, Falge E, Gu L, Olson R, Hollinger D, Running S, Anthoni P, Bernhofer Ch, Davis K, Fuentes J, Goldstein A, Katul G, Law BE, Lee X, Mahli Y, Meyers T, Munger W, Oechel W, Paw U, Pilegaard K, Schmid HP, Valentini R, Verma S, Vesala T, Wilson K, Wofsy SW (2001) FLUXNET: A new tool to study the temporal and spatial variability of ecosystem-scale carbon dioxide, water vapor and energy flux densities. Bull Am Meteorol Soc 82:2415-2434.

Brodribb $\mathrm{T}$ (1996) Dynamics of changing intercellular $\mathrm{CO}_{2}$ concentration $\left(\mathrm{c}_{\mathrm{i}}\right)$ during drought and determination of minimum functional $\mathrm{c}_{\mathrm{i}}$. Plant Physiol 111: 179-185.

Centritto M, Wahbi S, Serraj R, Chaves MM (2005) Effects of partial rootzone drying (PRD) on adult olive tree (Olea europaea) in field conditions under arid climate II. Photosynthetic responses. Agr Ecosyst Environ 106: 303-311.

Conejero W, Alarcón JJ, García-Orellana Y, Nicolás E, Torrecillas A (2007) Evaluation of sap flow and trunk diameter sensors for irrigation scheduling in early maturing peach trees. Tree Physiol 27:1753-1759.

Cuevas MV, Martín-Palomo MJ, Diaz-Espejo A, Torres-Ruiz JM, Rodriguez-Dominguez CM, Perez-Martin A, Pino-Mejías R, Fernández JE (2013) Assessing water stress in a hedgerow olive orchard from sap flow and trunk diameter measurements. Irrig Sci 31: 729-746.

DeJong TM (1983) $\mathrm{CO}_{2}$ assimilation characteristics of five Prunus tree fruit species. J Am Soc Hortic Sci 108:303-307.

Díaz-Espejo A, Walcroft AS, Fernández JE, Hafidi B, Palomo MJ, Girón IF (2006) Modeling photosynthesis in olive leaves under drought conditions. Tree Physiol 26:1445-1456.

Fereres E, Soriano MA (2007) Deficit irrigation for reducing agricultural water use. J Exp Bot 58: 147-159. 
Fernández JE, Green S, Caspari HW, Díaz-Espejo A, Cuevas MV (2008) The use of sap flow measurements for scheduling irrigation in olive, apple and Asian pear trees and in grapevines. Plant Soil 305:91-104.

Fernández JE, Cuevas MV (2010) Irrigation scheduling from stem diameter variations: a review. Agric For Meteorol 150: 135-151.

Fernández JE, Torres-Ruiz JM, Diaz-Espejo A, Montero A, Álvarez R, Jiménez MD, Cuerva J, Cuevas MV (2011) Use of maximum trunk diameter measurements to detect water stress in mature 'Arbequina' olive trees under deficit irrigation. Agric Water Manag 98: 1813-1821.

Foken T, Leuning R, Oncley SP, Mauder M, Aubinet M (2012) Corrections and data quality. In: M Aubinet et al. (eds) Eddy covariance: A Practical Guide to Measurement and Data Analysis, Springer, Dordrecht, Heidelberg, London, New York, pp 85-131.

Goldhamer DA, Viveros M (2000) Effects of preharvest irrigation cutoff durations and postharvest water deprivation on almond tree performance. Irrig Sci 19: 125-131.

Green S, Clothier B, Jardine B (2003) Theory and practical application of heat pulse to measure sap flow. Agron J 95: 1371-1379.

Jones HG (2004) Irrigation scheduling:advantages and pitfalls of plant-based methods. J Exp Bot 407: 24272436.

Kramer PJ, Boyer JS (1995) Water relations of plants and soils. Academic Press, Inc. San Diego, CA, pp 321 323.

Law BE, Falge E, Gu L, et al (2002) Environmental controls over carbon dioxide and water vapor exchange of terrestrial vegetation. Agric For Meteorol 113: 97-120.

López-Bernal A, Alcantara E, Testi L, Villalobos FJ (2010) Spatial sap flow and xylem anatomical characteristics in olive trees under different irrigation regimes. Tree Physiol 30: 1536-1544.

Mariscal MJ, Orgaz F, Villalobos FJ (2000) Modelling and measurement of radiation interception by olive canopies. Agric Forest Meteorol 100: 183-197. 
Marsal J, Girona J, Mata M (1997) Leaf water relation parameters in almond compared to hazelnut trees during a deficit irrigation period. J Am Soc Hortic Sci 122:582-587.

Mauder M, Foken T (2011) Documentation and instrumentation manual of the eddy-covariance software package TK3. Universität Bayreuth, Bayreuth.

Mitchell PD, Chalmers DJ (1982) The effect of reduced water supply on peach tree growth and yields. J Am Soc Hort Sci 107: 853-856.

Moriana A, Fereres E (2002) Plant indicators for scheduling irrigation of young olive trees. Irrig Sci 21: 8390.

Moriana A, Orgaz F, Pastor M, Fereres E (2003) Yield responses of mature olive orchard to water deficits. J Am Soc Hort Sci 123: 425-431.

Orgaz F, Villalobos FJ, Testi L, Fereres E (2007) A model of daily mean canopy conductance for calculating transpiration in olive canopies. Funct Plant Biol 34:178-188.

Pérez-Pérez JG, Romero P, Navarro JM, Botía P (2008) Response of sweet orange cv 'Lane late' to deficit irrigation in two rootstocks. I: water relations, leaf gas exchange and vegetative growth. Irrig Sci 26:415-425.

Pérez-Priego O, Testi L, Orgaz F, Villalobos FJ (2010) A large closed canopy chamber for measuring $\mathrm{CO}_{2}$ and water vapour exchange of whole trees. J Exp Bot 68: 131-138.

Romero P, Navarro JM, García F, Botía P (2004) Effects of regulated deficit irrigation during the pre-harvest period on gas exchange, leaf development and crop yield of mature almond trees. Tree Physiol 24:303-312.

Rosati A, Metcalf S, Buchner R, Fulton A, Lampinen B (2006) Tree water status and gas echange in walnut under drought, high temperature and vapour pressure deficit. J Hortic Sci Biotech 81:415-420.

Steduto P, Hsiao T, Fereres E (2007) On the conservative behavior of biomass water productivity. Irrig Sci 25:189-207. 
Swanson RH, Whitfield WA (1981) A numerical analysis of heat pulse velocity. Theory and practice. J Exp Bot 32: 221-239.

Swanson RH (1994) Significant historical developments in thermal methods for measuring sap flow in trees. Agric For Meteorol 72:113-132.

Testi L, Goldhamer DA Iniesta F, Salinas M (2008a) Crop wáter stress index is a sensitive water stress indicator in pistachio trees. Irrig Sci 26:395-405.

Testi L, Orgaz F, Villalobos FJ (2008b) Carbon Exchange and water use efficiency of a growing, irrigated olive orchard. Environ Exp Bot 63: 168-177.

Testi L, Villalobos FJ (2009) New approach for measuring low sap velocities in trees. Agric For Meteorol 149: $730-734$.

Tognetti R, Giovannelli A, Lavini A, Morelli G, Fragnito F, d'Andria R (2009) Assessing environmental controls over conductances through the soil-plant-atmosphere continuum in an experimental olive tree plantation of southern Italy. Agric For Meteorol 149:1229-1243.

Villalobos FJ, Testi L, Orgaz F, García-Tejera O, López-Bernal A, González-Dugo MV, Ballester-Lurbe C, Castel JR, Alarcón-Cabañero JJ, Nicolás EN, Girona J, Marsal J, Fereres E (2013) Modelling canopy conductance and transpiration in fruit tres: a simplified approach. Agric For Meteorol 171: 93-103.

Villalobos FJ, Perez-Priego O, Testi L, Morales A, Orgaz F (2012) Effects of wáter supply on carbon and water exchange of olive trees. Eur J Agron 40: 1-7.

Wieser G, Matyssek R, Köstner B, Oberhuber W (2003) Quantifying ozone uptake at the canopy level of spruce, pine and larch trees at the alpine timberline: an approach based on sap flow measurements. Environ Pollut 126:5-8.

Wieser G, Luis VC, Cuevas E (2006) Quantification of ozone uptake at the stand level in a Pinus canariensis forest in Tenerife, Canary Islands: an approach based on sap flow measurements. Environ Pollut 140:383-386. 
Wong SC, Cowan IR, Farquhar GD (1979) Stomatal conductance correlates with photosynthetic capacity. Nature 282:424-426. 


\section{Figure captions}

Figure 1: Daily values of reference evapotranspiration $\left(\mathrm{ET}_{0}\right)$ and rainfall (panels $\mathrm{A}-\mathrm{C}$ ) and evolution of the cumulative irrigation applied to the treatments $(\mathrm{CI}=$ control, $\mathrm{FI}=$ farm irrigation, $\mathrm{DI}=$ deficit irrigation $)$ (panels D-F) during the three experimental years.

Figure 2: Seasonal course of net ecosystem exchange (NEE), estimated net assimilation $(A)$ and vapour pressure deficit $(D)$ for the summer of 2011. NEE was determined with an eddy covariance system placed in the centre of the orchard while values of $A$ were deduced from the sap flow records of two trees in a separate experimental plot. In all cases values correspond to daytime means.

Figure 3: Plot of estimated net assimilation $(A)$ versus net ecosystem exchange (NEE), deduced from sap flow and eddy covariance systems, respectively. Data are daily values from 24 June 2011 (DOY 175) to 27 September 2011 (DOY 175). Dotted line indicates the 1:1 line.

Figure 4: Time course of predawn (closed symbols) and midday (open symbols) shoot water potential ( $\Psi$, panels A-C), calibrated transpiration ( $E_{p}$, panels D-F), estimated net assimilation ( $A$, panels G-I) and maximum trunk diameter (MXTD, panels J-L) for the three irrigation treatments $(\mathrm{CI}=$ control, $\mathrm{FI}=$ farm irrigation, $\mathrm{DI}=$ deficit irrigation) during the three experimental years.

Figure 5: Course of net assimilation $(A)$ estimated for the deficit irrigation (DI) and the farm treatments (FI) in relation to that of the control (CI) throughout the three years of experiment (i.e. ratio of either DI or FI values to those of $\mathrm{CI})$. 
Figure 1

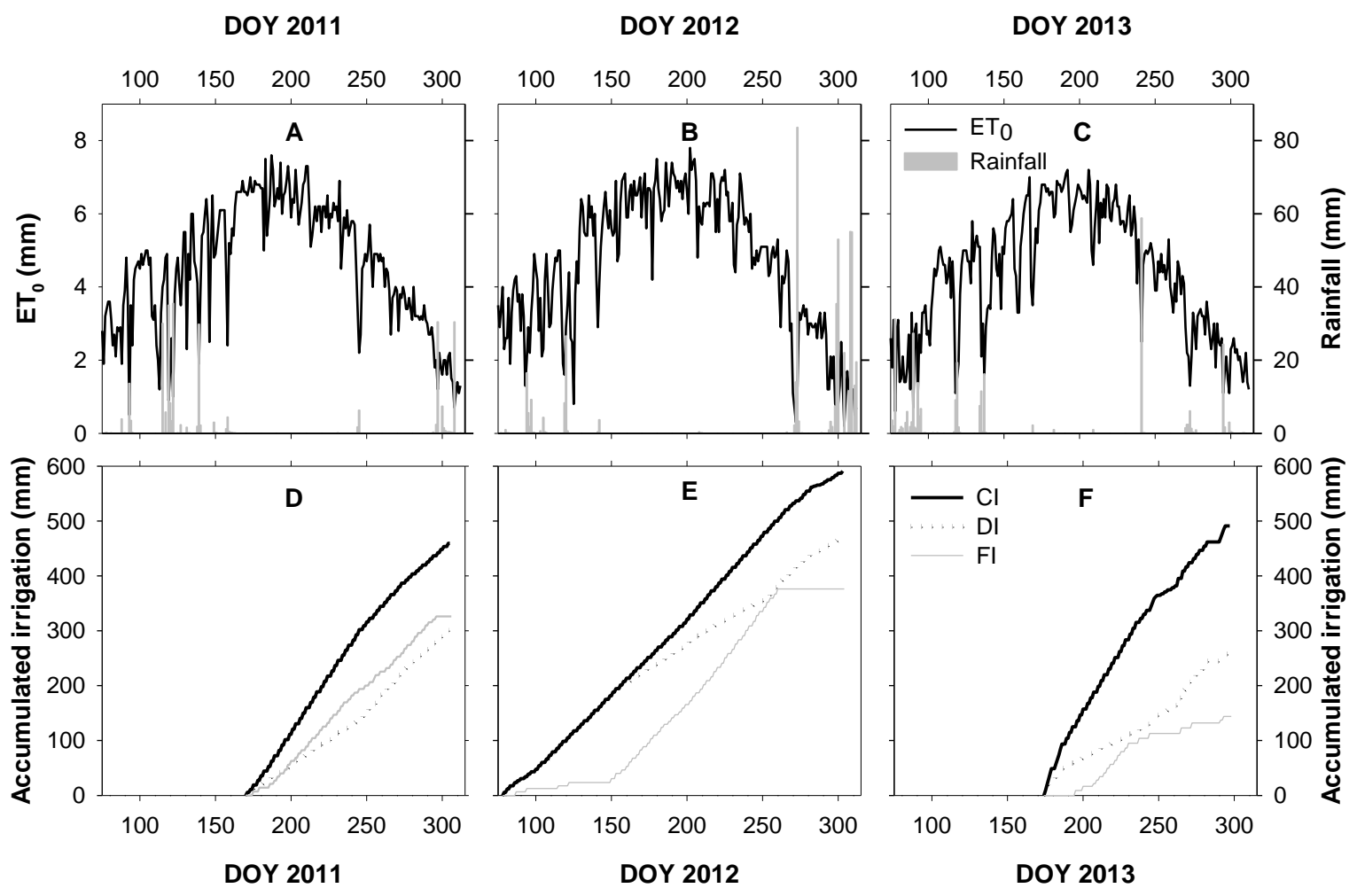


Figure 2:

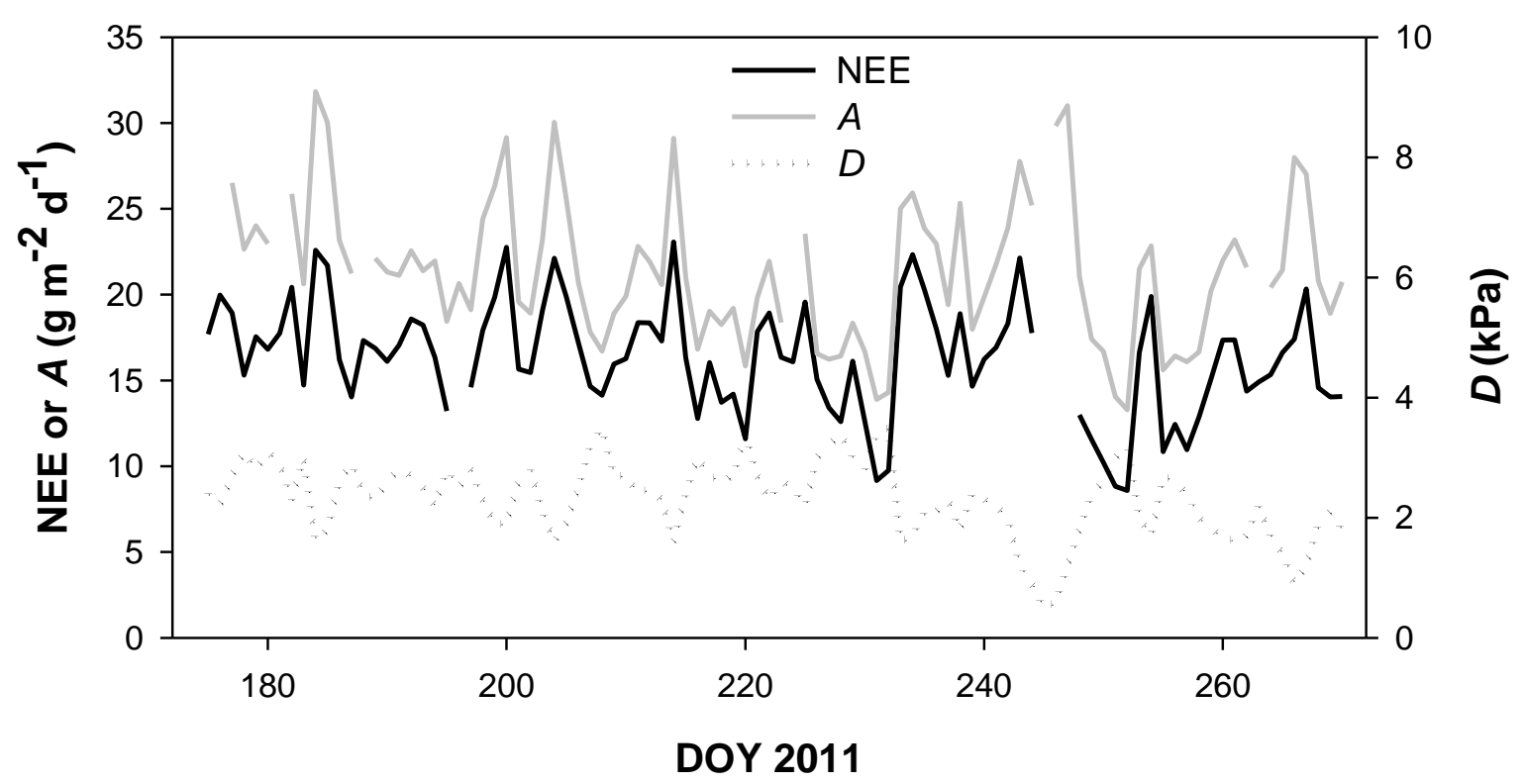


Figure 3:

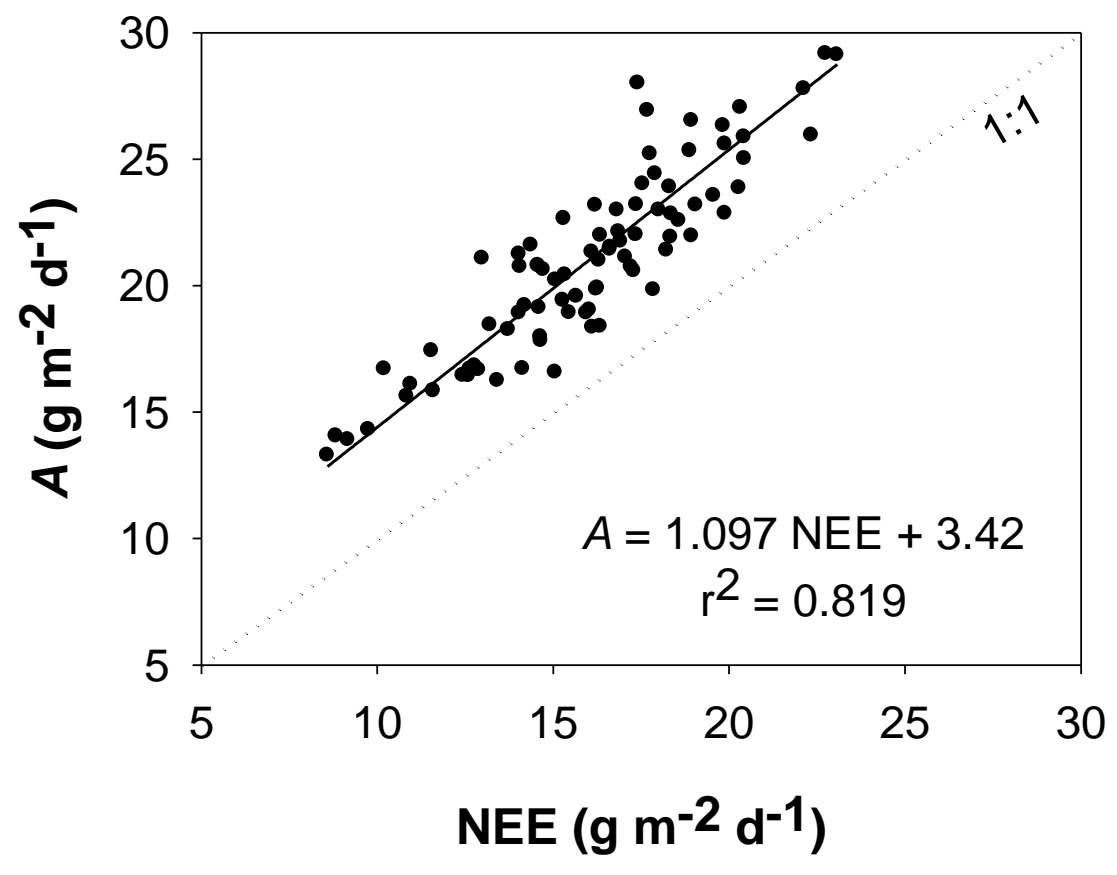


Figure 4:
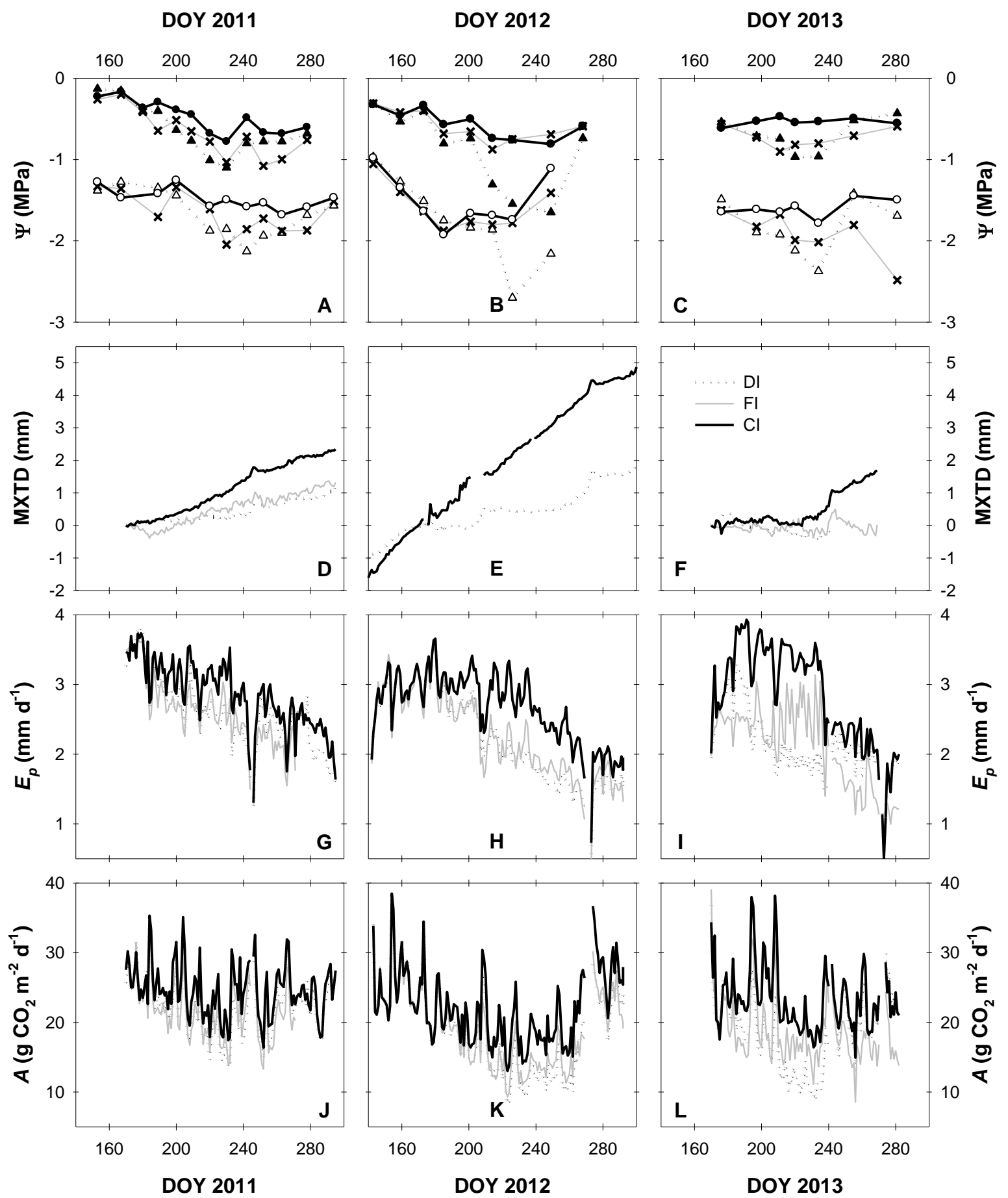
Figure 5:
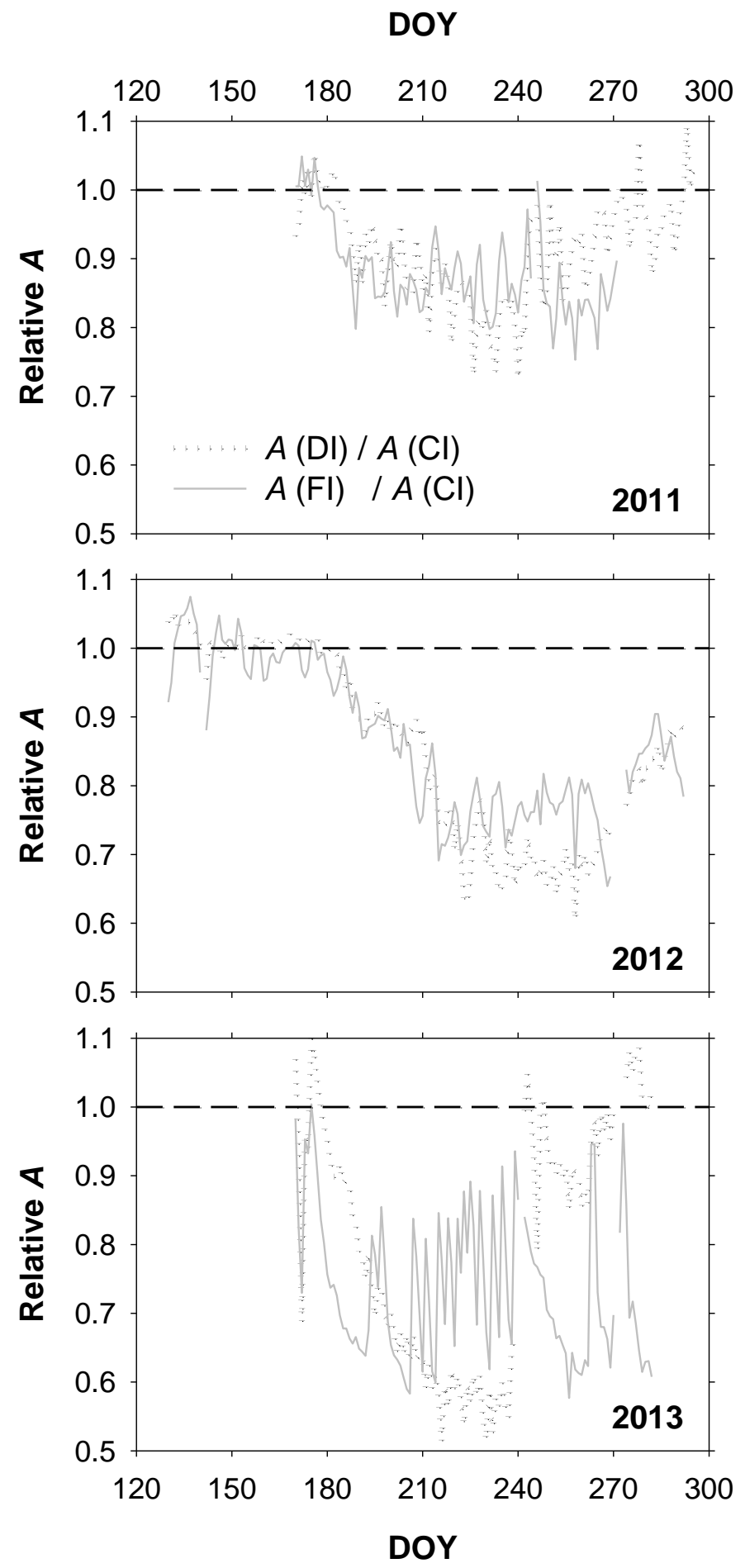